\title{
ANALISIS KETERSEDIAAN DAN KEBUTUHAN LAHAN PERUMAHAN DI PUSAT PELAYANAN KOTA (PPK) KOTA DEPOK (STUDI KASUS: KECAMATAN PANCORAN MAS DAN KECAMATAN SUKMAJAYA)
}

\author{
Asri Budiarto $^{(1)}$, Marselly Dwiputri $\left.{ }^{(2)}\right)$, Rizki Hambali ${ }^{(3)}$ \\ ${ }^{1}$ Universitas Indraprasta PGRI, Program Studi Arsitektur \\ Asribudiarto@gmail.com \\ ${ }^{2}$ Universitas Indraprasta PGRI, Program Studi Arsitektur \\ Marselly_wiputri@yahoo.com \\ ${ }^{3}$ Universitas Indraprasta PGRI, Program Studi Arsitektur \\ Rizkihambali@gmail.com
}

\begin{abstract}
:
The attraction of urban life and the life of the higher demands caused the population of Indonesia are turning to stay and activities in urban areas. The concentration of urban population needs to be addressed and anticipated early recall of some urban areas will appear. In its development, urban infrastructure, residential aspects should be the spearhead in the urban development often contributes to serious problems for urban life. Many problems originated from the aspect of urban settlements and urban infrastructure, like the share of land for housing needs with the availability of land so that the limited capacity of the land for housing and settlements, These issues often become latent problems not handled optimally. PPK Depok, inhabited by the population with human resources (HR) good quality and a high degree of social heterogeneity, both from the aspect of economy, education and governance guidelines. On the other hand the compact housing activities also cause irregularity residential area so that there is an area with a very high population density and limited land for housing this research seeks to identify and analyze the need of land for housing in the city of Depok PPK to can know the level of the land needs a means of settlement in PPK Depok to 10 years. In this study the author does a descriptive quantitative research methods. Researchers use quantitative data are presented with numbers and words and qualitative in form of words or explanation.
\end{abstract}

Key Words: Land Requirements, Population, PPK Depok City, Projection Facilities And Infrastructure

\begin{abstract}
Abstrak :
Daya tarik kehidupan perkotaan dan tuntutan kehidupan yang semakin tinggi menyebabkan penduduk Indonesia yang beralih untuk tinggal dan beraktivitas di kawasan perkotaan. Konsentrasi penduduk perkotaan perlu disikapi dan diantisipasi lebih awal karena beberapa persoalan wilayah perkotaan yang akan muncul. Dalam perkembangannya, aspek perumahan dalam pembangunan perkotaan seringkali menyumbang persoalan bagi kehidupan perkotaan itu sendiri, bermula dari aspek permukiman dan infrastruktur perkotaan, seperti tidak seimbangnya kebutuhan lahan untuk perumahan dengan ketersediaan lahan sehingga terbatasnya daya tampung lahan untuk perumahan dan permukiman, Masalah ini seringkali menjadi persoalan yang tidak tertangani secara optimal. PPK Kota Depok dihuni oleh penduduk dengan sumberdaya manusia yang berkualitas baik dan tingkat heterogenitas sosial yang tinggi, baik dari aspek ekonomi, pendidikan dan tata pergaulan. Padatnya aktifitas perumahan menyebabkan ketidakteraturan kawasan perumahan sehingga terdapat kawasan dengan kepadatan penduduk sangat tinggi dan keterbatasan lahan perumahan Dalam penelitian ini mengidentifikasi dan menganalisis kebutuhan lahan untuk sarana perumahan di PPK Kota Depok agar dapat mengetahui tingkat kebutuhan lahan sarana permukiman di PPK Kota Depok sampai 10 tahun kedepan. Metode penelitian dengan deskriptif kuantitatif menggunakan data kuantitatif yang disajikan dengan angka dan katakata dan kualitatif. Berdasarkan hasil penelitian, Ketersediaan daya tampung lahan untuk perumahan di PPK Kota Depok yaitu Kecamatan Pancoran Mas dan Kecamatan Sukmajaya pada tahun 2016 umumnya sudah tidak dapat tertampung, hampir seluruh kelurahan memiliki masalah keterbatasan lahan untuk perumahan penduduk di PPK Kota Depok pada tahun 2016, yaitu terdapat di Kelurahan Pancoran Mas, Kelurahan Depok Jaya, Kelurahan Depok, Kelurahan, dan Kelurahan Mekarjaya. Kekurangan lahan perumahan terbesar terdapat di Kelurahan Tirtajaya
\end{abstract} Kata-kunci :Kependudukan, Kebutuhan Lahan, PPK Kota Depok, Proyeksi Sarana dan Prasarana

\section{PENDAHULUAN}

Perkembangan jumlah penduduk pada suatu kawasan membawa perubahan besar pada kebutuhan dasar manusia yaitu kebutuhan akan papan beserta fasilitas penunjangnya. Kebutuhan dasar tersebut terus meningkat secara alamiah seiring kompleksitasnya kebutuhan hidup bermasyarakat, seperti kebutuhan untuk aktivitas sosial, aktivitas ekonomi, dan aktivitas pelayanan umum. Dari fenomena tersebut menuntut pula pembangunan sarana dan prasarana pada suatu kawasan guna menjaga kelangsungan hidup 
masyarakat di daerah perkotaan dalam rangka menuju kota berkelanjutan (Sustainable Cities)

Kota Depok mendorong Kawasan Pusat Pelayanan Kota (PPK) Kota Depok untuk terus berkembang. Dari data RTRW Kota Depok Tahun 2014-2034 menyebutkan tingkat pertumbuhan penduduk terus bertambah tiap tahunnya. Selain itu, perkembangan kecamatan ini dapat juga dilihat dari ketetapan RTRW Kota Depok menetapkan Kecamatan Pancoran Mas, Kecamatan Sukmajaya, dan Kecamatan Beji sebagai pusat pelayanan primer yang melayani seluruh wilayah Kota Depok, dalam hal ini PPK Kota Depok menjadikan salah satu titik pertumbuhan (growing points) di Kota Depok.

Guna menciptakan lingkungan permukiman yang berkembang, daya tampung untuk perumahan dan permukiman di PPK Kota Depok harus memadai. Hal ini yang kemudian menjadi suatu pertanyaan bagaimana ketersediaan lahan permukiman di PPK Kota Depok. Sehingga perlu dianalisis ketersediaan \& kebutuhan lahan permukiman yang kemudian menjadi rekomendasi untuk pihak terkait dalam menyediakan lahan perumahan dan permukiman di PPK Kota Depok.

\section{Kajian Teori \\ Pengertian Tata Guna Lahan}

Tata guna lahan adalah pengaturan mengenai penggunaan lahan dimana memerlukan sumberdaya manusia dan sumberdaya lainnya. terdiri dari lahan tebangun dan lahan terbuka (Markus,2006)

\section{Perumahan}

Kelompok rumah yang berfungsi sebagai lingkungan tempat tinggal atau lingkungan hunian yang dilengkapi dengan prasarana dan sarana lingkungan. Perumahan adalah kumpulan rumah sebagai bagian dari permukiman, baik perkotaan maupun perdesaan, yang dilengkapi dengan prasarana, sarana, dan utilitas umum sebagai hasil upaya pemenuhan rumah yang layak huni. (Sumber: UU No. 1 Tahun 2011 Tentang Perumahan dan Kawasan Permukiman).

Standar Nasional Indonesia tentang Penataan Sarana Permukiman

SNI penataan sarana permukiman merupakan kerangka acuan yang berfungsi sebagai perencanaan, perancangan serta kebutuhan sarana dalam ruang. Penentuan asumsi dasar satuan unit lingkungan dapat dipertimbangkan dan disesuaikan dengan kondisi konteks lokal yang telah dimiliki. Berdasarkan
SNI Tata Cara Perencanaan Lingkungan Perumahan No. 03-1733-2004 terdapat asumsi dasar sebagai berikut :

a. Jumlah penghuni rumah rata-rata : 5 jiwa

b. bila $1 \mathrm{kk}$ terkecil rata-rata terdiri dari 5 orang (ayah $+\mathrm{ibu}+3$ anak) maka kebutuhan luas lantai minimum dihitung sebagai berikut : - Luas lantai utama $=(2 \times 9,6)+$ $(3 \times 4,8) \mathrm{m} 2=33,6 \mathrm{~m} 2$

- Luas lantai pelayanan $=50 \% \times 33,6$ $\mathrm{m} 2=16,8 \mathrm{~m} 2-$ Total Luas Lantai $=51 \mathrm{~m} 2$

c. Jika koefisien dasar bangunan $50 \%$, maka luas kaveling minimum untuk keluarga dengan anggota 5 orang adalah sebesar $100 \mathrm{~m}^{2}$

\section{METODOLOGI}

Dalam penelitian ini penulis melakukan penelitian tentang Analisis proyeksi Kebutuhan lahan Perumahan dan Permukiman. Penulis mengumpulkan data dengan melakukan Observasi lapangan, Dokumentasi, serta simak dokumen. Dalam menganlisis data penulis menggunakan teknik analisis deskriptif kualitatif-kuantitatif. Peneliti menggunakan data kuantitatif. dimana data kuantitatif adalah data yang disajikan dalam bentuk angka-angka. Namun peneliti juga menggunakan data kualitatif yang merupakan data yang disajikan dalam bentuk kata-kata atau penjelasan. Selain itu penulis menggunakan analisis spasial dimana sebagai acuan menyajikan data dalam bentuk Peta.

\section{Analisis proyeksi}

Perkiraan kebutuhan Sarana permukiman tergantung dari jumlah penduduk. Untuk itu data jumlah penduduk pada daerah yang dikaji sangat diperlukan dari tahun ke tahun untuk di proyeksikan pada tahun-tahun yang akan datang. Hasil analisis pertumbuhan penduduk ini, Guna mendapat hasil kebutuhan sarana dalam 5 tahun kedepan, peneliti menggunakan analisis proyeksi geometrik. Selanjutnya di pergunakan sebagai dasar perhitungan kebutuhan lahan Sarana perumahan dan permukiman. beberapa faktor yang sangat mempengaruhi proyeksi kebutuhan Sarana Permukiman adalah

a. Jumlah penduduk

b. Kecepatan pertumbuhan penduduk

c. Kurun waktu proyeksi

Rumus Geometrik

$\mathrm{Pn}=\mathrm{Po}[1+\mathrm{r}]$

$\mathrm{Pn}=$ penduduk pada tahun $\mathrm{n}$

Po $=$ penduduk pada tahun awal

$1=$ angka konstanta 

$\mathrm{r}=$ angka pertumbuhan penduduk (dalam persen)
$\mathrm{n}=$ jumlah rentang tahun dari awal hingga tahun $n$

\section{HASIL DAN PEMBAHASAN}

\section{Luas Wilayah}

Lokasi penelitian di Kawasan Pusat Pelayanan Kota Depok adalah lahan seluas kurang lebih 1.530 Ha yang berada di 2 (dua) Kecamatan yang berada di Kecamatan Pancoran Mas dan Sukmajaya, seperti yang terlihat pada tabel dibawah ini :

Tabel 1. Lokasi Kawasan Penelitian

\begin{tabular}{|c|c|c|c|c|}
\hline No & $N$ & $\begin{array}{l}\text { Keca } \\
\text { matan }\end{array}$ & $\begin{array}{c}\text { Kelura } \\
\text { han }\end{array}$ & Luas (ha) \\
\hline \multirow{3}{*}{1} & \multirow{3}{*}{2} & \multirow{3}{*}{ Pancoran Mas } & Depok & 3 \\
\hline & & & Depok & 1 \\
\hline & & & Pancor & 3 \\
\hline \multirow[b]{2}{*}{2} & \multirow[t]{2}{*}{. } & \multirow{2}{*}{ Sukmajaya } & Mekari & 3 \\
\hline & & & Tirtajav & 3 \\
\hline
\end{tabular}

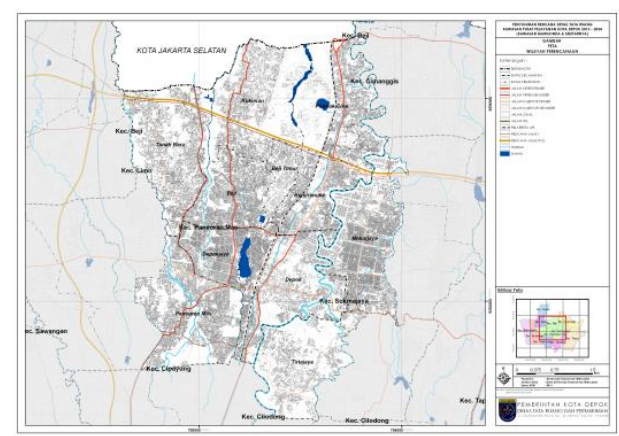

Gambar 1. Peta Lokasi Penelitian Sumber : Peneliti, 2018

\section{Proyeksi Jumlah Penduduk}

Pada tabel dibawah ini menunjukan Proyeksi jumlah penduduk dari tahun 2016 hingga tahun 2026 berdasarkan data jumlah penduduk dalam kurun waktu 5 tahun terakhir, yaitu tahun 2012-2016

Tabel 2. Jumlah Penduduk Tahun 2012-2016

\begin{tabular}{lccccc}
\hline KECAMATAN / KELURAHAN & $\mathbf{2 0 1 2}$ & $\mathbf{2 0 1 3}$ & $\mathbf{2 0 1 4}$ & $\mathbf{2 0 1 5}$ & $\mathbf{2 0 1 6}$ \\
\hline PANCORAN MAS & 119.809 & 125.056 & 130.533 & 136.249 & 142.215 \\
\hline Pancoran Mas & 55.310 & 57.732 & 60.260 & 62.899 & 65.653 \\
\hline Depok Jaya & 27.990 & 29.216 & 30.496 & 31.831 & 33.225 \\
\hline Depok & 36.509 & 38.108 & 39.777 & 41.519 & 43.337 \\
\hline SUKVAJAYA & 110.927 & 115.786 & $\mathbf{1 2 0 . 8 5 6}$ & $\mathbf{1 2 6 . 1 4 8}$ & $\mathbf{1 3 1 . 6 7 2}$ \\
\hline Mekajaya & 98.361 & 102.669 & 107.165 & 111.857 & 116.756 \\
\hline Tirtajaya & 12.566 & 13.117 & 13.691 & 14.291 & 14.916 \\
\hline
\end{tabular}

Sumber : Depok Dalam Angka, 2017

Berdasarkan data jumlah penduduk tahun 2012 sampai pada tahun 2016, jumlah penduduk terbesar terdapat di kelurahan Mekarjaya yaitu sebanyak 116.756 jiwa, sedangkan jumlah penduduk terendah terdapat di Kelurahan Depok jaya yaitu sebanyak 14.916 jiwa

Tabel 3. Proyeksi Jumlah Penduduk

\begin{tabular}{rlrrr}
\hline NO & \multicolumn{1}{c}{$\begin{array}{c}\text { KECAMATAN / } \\
\text { KELURAHAN }\end{array}$} & 2016 & 2021 & 2026 \\
\hline I & PANCORAN MAS & 142.215 & 176.203 & 218.314 \\
\hline 1 & Pancoran Mas & 65.653 & 81.344 & 100.784 \\
\hline 2 & Depok Jaya & 33.225 & 41.165 & 51.004 \\
\hline 3 & Depok & 43.337 & 53.694 & 66.526 \\
\hline & & & & \\
\hline II & SUKMAJAYA & 131.672 & 163.141 & 202.130 \\
\hline 1 & Mekarjaya & 116.756 & 144.660 & 179.232 \\
\hline 2 & Tirtajaya & 14.916 & 18.481 & 22.898 \\
\hline
\end{tabular}

Berdasarkan hasil analisis proyeksi jumlah penduduk PPK Kota Depok per 10 (sepuluh) tahun sampai pada Tahun 2026, jumlah penduduk tertinggi terdapat di Kelurahan Mekarjaya Kecamatan Sukmajaya sebanyak 179.232 jiwa dan terendah berada di Kelurahan Tirtajaya Kecamatan Sukmajaya sebanyak 22.898 jiwa

Tabel 4. Kepadatan Penduduk Tahun 2016-2026

\begin{tabular}{rlrrr}
\hline \multirow{4}{*}{ NO } & KELURAHAN / KECAMATAN & 2016 & 2021 & 2026 \\
\hline I & PANCORAN MAS & 586 & 726 & 900 \\
\hline 1 & Pancoran Mas & 188 & 232 & 288 \\
\hline 2 & Depok Jaya & 280 & 347 & 430 \\
\hline 3 & Depok & 118 & 147 & 182 \\
\hline & & & & \\
\hline II & SUKMAJAYA & 411 & 508 & 630 \\
\hline 1 & Mekarjaya & 359 & 444 & 551 \\
\hline 2 & Tirtajaya & 52 & 64 & 79 \\
\hline & PPKKOTA DEPOK & 997 & 1234 & 1530 \\
\hline
\end{tabular}

Sumber : Hasil Analisis,2018

Berdasarkan hasil analisis kepadatan penduduk PPK Kota Depok Tahun 2026, kepadatan penduduk tertinggi terdapat di Kelurahan Depok jaya Kecamatan pancoran Mas sebanyak 430 jiwa/ha dan terendah berada di Kelurahan Tirtajaya Kecamatan Sukmajaya sebanyak 79 jiwa/ha

\section{Penggunaan Lahan}

Berdasarkan RTRW Kota Depok Tahun 2014-2034 dapat diketahui pada penggunaan lahan di PPK Kota Depok Berdasarkan penggunaan lahan bahwa terjadi perubahan fungsi lahan dari kawasan non terbangun menjadi kawasan terbangun. Bukan hanya luas lahan untuk permukiman yang mengalami peningkatan akan tetapi terjadi juga pada guna lahan lain, seperti perdagangan dan jasa yang mengalami 
peningkatan yaitu pada tahun 2009 luasnya sebesar 96,01 Ha dan pada tahun 2014 menjadi 120, 54 Ha. Perubahan luas lahan pada guna lahan perdagangan dapat menyebabkan pengurangan pada guna lahan lain, terjadi pengurangan pada guna lahan RTNH yang terjadi di hampir seluruh kelurahan, begitupun dengan sawah yang mengalami penurunan luas lahan yang terjadi di Pancoran Mas. Untuk kebun campuran hampir di seluruh kelurahan mengalami penurunan luas lahan. Sedangkan penggunaan lahan yang mengalami peningkatan luas yaitu Perdagangan dan Jasa dan Permukiman.

Berkembangnya permukiman di Kawasan PPK Kota Depok membawa dampak yang cukup besar terhadap beralihnya fungsi lahan pertaniaan ke permukiman sehingga perlu adanya pembatasan dalam pemberian ijin untuk pengembangan perumahan terutama pada lahanlahan yang berfungsi sebagai sawah irigasi, selain itu juga pengembangan perumahan di Kawasan PPK Kota Depok harus sudah mengarah ke pembangunan perumahan secara vertikal.

Tabel 5. Tata Guna Lahan Perumahan PPK Depok Tahun 2016 Dalam Hektar (Ha)

\begin{tabular}{clc}
\hline No & Kelurahan & $\begin{array}{c}\text { Perumahan } \\
\text { /Permukiman }\end{array}$ \\
\hline I & Pancoran Mas & 432,85 \\
\hline 1 & Pancoran Mas & 180,46 \\
\hline 2 & Depok Jaya & 90,42 \\
\hline 3 & Depok & 161,97 \\
\hline II & Sukmajaya & 287,8 \\
\hline 1 & Tirtajaya & 70,45 \\
\hline $\mathbf{2}$ & Mekarjaya & $\mathbf{2 1 7 , 3 5}$ \\
\hline & Jumlah & $\mathbf{7 2 0 , 6 5}$ \\
\hline
\end{tabular}

Sumber : Pemerintah Kota Depok, 2017

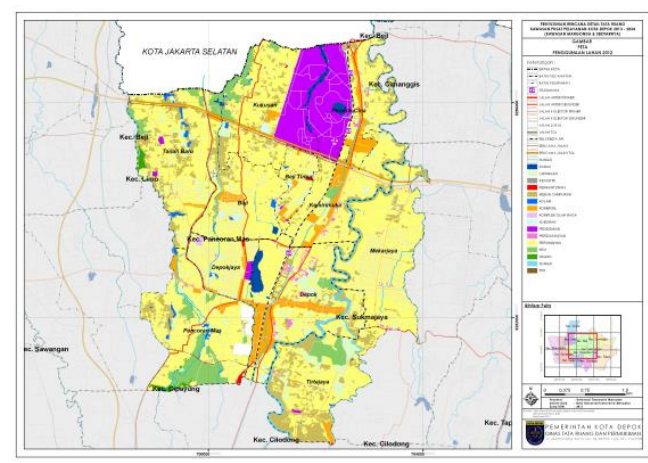

Gambar 1. Peta Guna Lahan Sumber : Peneliti, 2014

\section{Analisis Kebutuhan Unit Rumah}

Terdapat kebutuhan unit perumahan dilihat dari standar SNI Perumahan Lingkungan yaitu 1 unit rumah Per 1 KK (Kepala Keluarga) sebanyak 5 jiwa. Untuk lebih jelas dapat dilihat dibawah ini :

Tabel 6. Kebutuhan Unit Rumah Tahun 2016

\begin{tabular}{clrr} 
NO & Kecamatan / Kelurahan & $\begin{array}{c}\text { Jumlah } \\
\text { Penduduk }\end{array}$ & $\begin{array}{c}\text { Kebutuhan } \\
\text { Unit } \\
\text { Rumah }\end{array}$ \\
\hline II & PANCORAN MAS & 142.215 & 28.443 \\
\hline 1 & Pancoran Mas & 65.653 & 13.131 \\
\hline 2 & Depok Jaya & 33.225 & 6.645 \\
\hline 3 & Depok & 43.337 & 8.667 \\
\hline III & SUKMAJAYA & 131.672 & 26.334 \\
\hline 1 & Mekarjaya & 116.756 & 23.351 \\
\hline 2 & Tirtajaya & 14.916 & 2.983 \\
\hline & Jumlah & $\mathbf{2 7 3 . 8 8 7}$ & $\mathbf{5 4 . 7 7 7}$ \\
\hline
\end{tabular}

Sumber : Hasil Analisis, 2018

Kebutuhan unit rumah terbesar pada tahun 2016 terdapat di Kelurahan Mekarjaya yaitu sebanyak 23.351 unit rumah, sedangkan kebutuhan unit rumah terendah terdapat di Kelurahan Tirtajaya yaitu sebanyak 2.983 unit rumah di PPK Kota Depok.

Tabel 7. Proyeksi Kebutuhan Unit Rumah

\begin{tabular}{|c|c|c|c|}
\hline No & $\begin{array}{l}\text { KECAMATAN / } \\
\text { KELURAHAN }\end{array}$ & $\begin{array}{c}\text { Jumlah } \\
\text { Penduduk }\end{array}$ & $\begin{array}{c}\text { Kebutuhan } \\
\text { Unit } \\
\text { Rumah } \\
\end{array}$ \\
\hline II & PANCORAN MAS & 218.314 & 43.663 \\
\hline 1 & Pancoran Mas & 100.784 & 20.157 \\
\hline 2 & Depok Jaya & 51.004 & 10.201 \\
\hline 3 & Depok & 66.526 & 13.305 \\
\hline III & SUKMAJAYA & 202.130 & 40.426 \\
\hline 1 & Mekarjaya & 179.232 & 35.846 \\
\hline 2 & Tirtajaya & 22.898 & 4.580 \\
\hline \multicolumn{2}{|r|}{ Jumlah } & 420.444 & 84.089 \\
\hline
\end{tabular}

Berdasarkan data diatas diketahui kebutuhan unit rumah terbesar pada tahun 2026 terdapat di Kelurahan Mekarjaya yaitu sebanyak 35.846 unit rumah, sedangkan kebutuhan unit rumah terendah terdapat di Kelurahan Tirtajaya yaitu sebanyak 4.580 unit rumah di PPK Kota Depok.

\section{Analisis Kebutuhan Lahan Perumahan}

Ketersediaan lahan untuk kebutuhan sarana perumahan di PPK Kota Depok berdasarkan hasil populasi penduduk sampai pada 10 (sepuluh) tahun kedepan dengan menggunakan skenario kebutuhan lahan perumahan $1: 3: 6$.

Skenario kebutuhan lahan ini berdasarkan RDTR Kota Depok Tahun 2013-2034, yaitu Rencana kebutuhan perumahan di lokasi perencanaan akan berpatokan pada asumsi sebagai berikut:

a. Konsep Penyediaan Perumahan : $1: 3: 6$

b. $1 \mathrm{KK}$ : 5 Orang

c. Kavling Kepadatan Tinggi : $150 \mathrm{~m}^{2}$

d. Kavling Kepadatan Sedang : $140 \mathrm{~m}^{2}$ 
e. Kavling Kepadatan Rendah : $120 \mathrm{~m}^{2}$

Untuk lebih jelas dapat dilihat dibawah ini :

Tabel 8. Kebutuhan Luas Lahan Perumahan Tahun 2016

\begin{tabular}{|c|c|c|c|c|c|c|}
\hline \multirow{2}{*}{ No } & \multirow{2}{*}{$\begin{array}{l}\text { Kecamatan / } \\
\text { kelurahan }\end{array}$} & \multirow{2}{*}{2016} & \multirow{2}{*}{$\begin{array}{l}\text { Jumlah } \\
\text { KK }\end{array}$} & \multicolumn{3}{|c|}{ Kebutuhan Luas (ha) } \\
\hline & & & & 150 & 140 & 120 \\
\hline II & $\begin{array}{l}\text { PANCORAN } \\
\text { MAS }\end{array}$ & 142.215 & 28.443 & 42,66 & 119,46 & 204,79 \\
\hline 1 & Pancoran Mas & 65.653 & 13.131 & 19,70 & 55,15 & 94,54 \\
\hline 2 & Depok Jaya & 33.225 & 6.645 & 9,98 & 27,92 & 47,84 \\
\hline 3 & Depok & 43.337 & 8.667 & 13,01 & 36,40 & 62,40 \\
\hline III & SUKMAJAYA & 131.672 & 26.334 & 39,50 & 110,60 & 189,61 \\
\hline 1 & Mekarjaya & 116.756 & 23.351 & 35,03 & 98,07 & 168,13 \\
\hline 2 & Tirtajaya & 14.916 & 2.983 & 4,47 & 12,53 & 21,48 \\
\hline & Jumlah & 273.887 & 54.777 & 164,33 & 460,12 & 788,80 \\
\hline
\end{tabular}

Sumber : Hasil Analisis, 2018

Berdasarkan data diatas diketahui kebutuhan luas lahan terbesar untuk sarana perumahan di PPK Kota Depok pada tahun 2016 terdapat di Kelurahan Mekarjaya yaitu sebesar 301,23 Ha, sedangkan kebutuhan luas lahan terendah terdapat di Kelurahan Tirtajaya yaitu sebesar 38,48 Ha di PPK Kota Depok.

\section{Analisis Perbandingan Kebutuhan Luas Lahan Perumahan Tahun 2016 dan Tahun 2026}

Proyeksi kebutuhan luas lahan perumahan PPK Kota Depok pada tahun 2026 dapat dilihat pada tabel dibawah ini sebagai berikut :

Tabel 10. Perbandingan Kebutuhan Luas Lahan Perumahan Tahun 2016

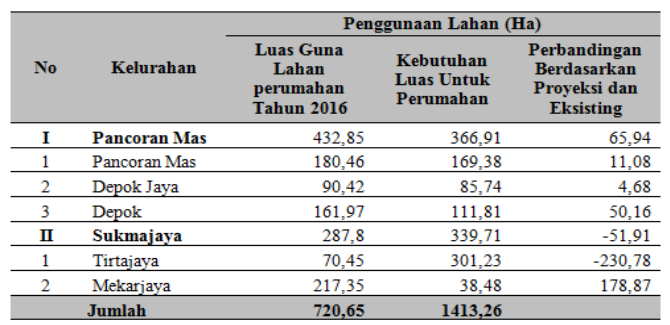

Berdasarkan tabel diatas diketahui ketersediaan lahan untuk perumahan di PPK Kota Depok tahun 2106, berdasarkan perbandingan eksisting dan proyeksi kebutuhan lahan, terdapat kelurahan yang memiliki masalah keterbatasan lahan untuk perumahan penduduk di PPK Kota Depok, yaitu terdapat di Kelurahan Tirtajaya di Kecamatan Sukmajaya, terdapat keterbatasan daya tampung untuk perumahan sebesar 230,78 Ha. Sedangkan untuk kelurahan lainnya masih dapat menampung untuk sarana perumahan di PPK Kota Depok.

Berdasarkan perbandingan daya tampung atau ketersediaan luas lahan perumahan antara luas eksisting (Supply) untuk guna lahan perumahan dan kebutuhan luas lahan (Demand) yang harus dipenuhi pemerintah Kota Depok pada tahun 2026 dapat dilihat dibawah ini sebagai berikut :

Tabel 11. Perbandingan Kebutuhan Luas Guna Lahan Perumahan PPK Kota Depok Tahun

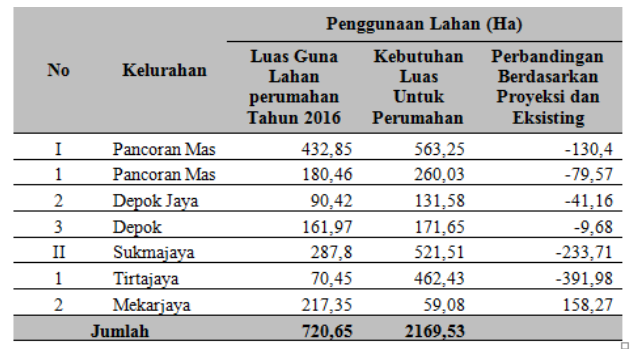

Sumber : Hasil Analisis, 2018

Berdasarkan tabel diatas diketahui ketersediaan lahan untuk perumahan di PPK Kota Depok tahun 2026, berdasarkan perbandingan eksisting dan proyeksi kebutuhan lahan, hampir seluruh kelurahan memiliki masalah keterbatasan lahan untuk perumahan penduduk di PPK Kota Depok pada tahun 2016, yaitu terdapat di Kelurahan Pancoran Mas, Kelurahan Depok Jaya, Kelurahan Depok, Kelurahan, dan Kelurahan Mekarjaya. Kekurangan lahan perumahan terbesar terdapat di Kelurahan Tirtajaya sebesar 391,98 Ha. Sedangkan untuk kelurahan Mekarjaya berdasarkan hasil analisis untuk daya tampung lahan masih memadai, yaitu sebesar 158,27. Untuk lebih jelas dapat dilihat pada peta dibawah ini sebagai berikut :

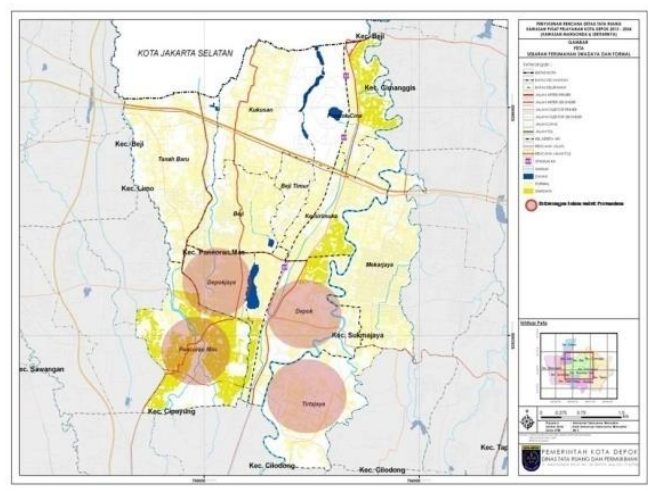

Gambar 2. Peta Kebutuhan Lahan untuk Perumahan Tahun 2026

\section{PENUTUP}

\section{Simpulan}

1. Ketersediaan daya tampung lahan untuk perumahan di PPK Kota Depok yaitu Kecamatan Pancoran Mas dan Kecamatan Sukmajaya pada tahun 2016 umumnya telah memadai, hanya 1 kelurahan saja yang tidak dapat menampung lahan untuk perumahan 
dan permukiman yaitu di Kelurahan Tirtajaya sebesar 230,78 Ha.

2. Ketersediaan daya tampung lahan untuk perumahan di PPK Kota Depok yaitu Kecamatan Pancoran Mas dan Kecamatan Sukmajaya pada tahun 2026 umumnya sudah tidak dapat tertampung, hanya 1 kelurahan saja yang masih menampung lahan untuk perumahan dan permukiman yaitu di Kelurahan Mekarjaya sebesar 158,27 Ha.

3. Berdasarkan RDTR Kota Depok akan direncanakan pengembangan perumahan vertikal yang bertujuan untuk mengarahkan pengembangan perumahan di PPK Kota Depok agar tidak berkembang secara sporadis, diperkirakan pengembangan perumahan horizontal harus dibatasi, hal ini disebabkan penggunaan lahan yang masih dapat dimanfaatkan sudah tidak dapat menampung kebutuhan perumahan. Maka perumahan akan diarahkan menjadi perumahan vertikal, misalnya rumah susun (rusunawa, rusunami, dan rusuna) maupun apartemen.

\section{Saran}

1. Perlu adanya perhatian dari pemerintah untuk sarana yang belum tersedia di kecamatan di PPK Kota Depok khususnya sarana kesehatan. Dengan ketersediaan kebutuhan fasilitas tersebut, diharapakan pelayananya dapat menjangkau seluruh lingkungan permukiman yang ada di kecamatan di PPK Kota Depok

2. Perlu adanya evaluasi dari pemerintah untuk kebutuhan luas lahan perumahan dan permukiman yang tidak merata antara satu Kelurahan dengan kelurahan lainnya.

\section{DAFTAR PUSTAKA}

Anonimous, Badan Standarisasi Nasional. 2004. Tata Cara Perencanaan Lingkungan Perumahan Di Perkotaan. Bandung: Penerbit Badan Standarisasi Nasional.

Anonimous, Peraturan Pemerintah Republik Indonesia Nomor 88 Tahun 2014 Tentang Pembinaan Penyelenggaraan Perumahan Dan Kawasan Permukiman.

Anonimous, Undang-Undang No 4 Tahun 1992 tentang Perumahan dan Kawasan Permukiman.

Clark, Isobel. 2001. Practical Geostatistics. Central Scotland: Geostokos Limited.
Lembaga Demografi FE UI. 1981. Dasar-dasar demografi. Jakarta : Lembaga Penerbit Lembaga Fakultas UI.

Sugiyono. 2013. Metode Penelitian Pendidikan Pendekatan Kuantitatif, Kualitatif dan $R \& D$. Bandung: Alfabeta

Yunus, S.H. 1982, 1999. Struktur Tata ruang kota. Yogyakarta: Penerbit Pustaka Pelajar.

SNI 03-1733-2004 tentang Tata Cara PerencanaanLingkunganPerumahan di Perkotaan. BSN

Zahnd, Markus. (2006). Perancangan Kota Secara Terpadu. Yogyakarta: Kanisius. 